\title{
A Perspective Research on Information Systems in Tourism Sector in Kerala
}

\author{
M.R. Dileep, K.S.Chandrasekar
}

\begin{abstract}
Tourism, a multi-dimensional and multi-faceted activity with diverse social, cultural, economic and ecological impacts, got evolved as one of the largest and most significant economic sectors in the world. The lure of tourism as an engine of economic growth and diversification has been urging each and every country in the world to develop and promote it in the most possible manner (Dileep, 2018). As per the current projections, tourism is tend to grow further and it will remain as one of the most vibrant, growing and economically useful activities in the world having wide social and cultural ramifications in the years to come as well. Being an amalgam of industries, this sector includes a diverse range of industries like, intermediaries; transportation; accommodation; entertainment and recreation; shopping; hospitality; and infrastructure. Complex linkages and interrelationships exist among the various individual sectors of the tourism industry. The post second world war era has witnessed tremendous growth of tourism and in the same era has recorded the evolution and growth of information and communication technology as well. Information Technology has become one of the most fundamental and vital components of the successful businesses and organizations and is a major facilitator. In the growth of tourism as a major social phenomenon in the 21st century, Information and communication technology (ICT) too had played significant roles. Indeed, the relationship between tourism and ICT was symbiotic as well, since the latter sector got many opportunities for the application of it in the tourism sector, like in the air transportation which was a pioneer in developing transaction systems for handling the cumbersome booking data in the 1950s and 60s. Information systems for the core of ICT applications in businesses and organisations.

Tourism Sector too has been using different types of information systems intensively in the international scenario. Kerala, one of the late entrants in the international tourism, has turned to be successful international tourist destinations within a few decades of time. The number of tourism arrivals has been registering consistent growth and the industry got expanded exponentially in Kerala. To compete globally, tourism of anywhere requires a variety of information systems. Kerala tourism industry is also not an exception to this. In this context, a study on the current usage of information systems in the tourism sector in Kerala seems inevitable. The study has to focus upon the types of information systems used by the tourism industry in Kerala, efficiency as well as the impacts of the usage of such information systems by the industry, comparing the scenario with the international standards and also to discuss about the future to suggest suitable solutions to look ahead to have more competence by the Kerala tourism.
\end{abstract}

Keywords: Information and communication technology (ICT).

\section{INTRODUCTION}

The study primarily aims at finding out a clear picture about the current usage of information systems in the tourism

Revised Manuscript Received on September 22, 2019.

Dr.M.R. Dileep, Vice Principal and Head-Department of Tourism, Pazhassiraja College, Wayanad dileepmadhav@gmail.com

Dr.K.S.Chandrasekar, Professor and Dean, IMK, University of Kerala, Trivandrumkscnair@gmail.com sector. Discussing about the future is also entertained in this study. The specific objectives are as follows.

- To study about the various types of information systems functioning in the tourism sector in Kerala.

- To find out the efficiency of such systems for the maximum utilization of Information technology in tourism in Kerala.

- To compare those systems with international standards.

- To identify the impacts especially the benefits so far by the implementation and usage of information systems in tourism.

- To give suggestions, and to formulate model for further developments in the area of information systems in tourism based on the findings of the study.

\section{LITERATURE REVIEW}

Information Technology is today's buzzword emerged during the second half of the last century. The role and importance of application of Information Technology in almost all spheres of humankind is astonishing and is ever increasing. As far as business organizations are concerned, Information Technology has become a strategic necessity and has become a vital component of successful business organizations. Poon (1993) defines Information Technology as the collective term given to the most recent development in the mode (electronic) and the mechanisms (computers and communication technologies) used for the acquisition, processing, analysis, storage, retrieval, dissemination and application of information. In a business organization information system provides information support for decision makers at various management and decision levels. In this context 'information' is a resource produced by information systems that is vital to the operations as well as management of business organizations. According to Stair and Reynolds (2001) Information System is 'a set of interrelated components that collect, manipulate, and disseminate data and information and provide a feedback mechanism to meet an objective. The biggest advantage of an information system is that it can provide the most cost effective resource for the organization (Jaiswal and Mital 2004). Different kinds of computer based information systems are there, and the computer is used as a fundamental component of them. Apart from the predominant usage of information systems in these business organizations, other computer information systems were evolved and the example is Geographic Information Systems (GIS) that can handle spatial data. According to Laudon andLaudon (2004), there are six major types of systems in contemporary organizations. The most fundamental system is the transaction processing system 
(TPS). Knowledge level systems support clerical, managerial and professional workers. They consist of office systems for increasing data workers' productivity. The Management Information System (MIS) uses the information from a TPS to generate information useful for management decision making. Decision Support Systems (DSS) is an information system to support problem specific decision making. Executive Support Systems (ESS) supports the strategic level by providing a generalized computing and communications environment to assist senior management's decision making. Artificial Intelligence (AI) includes a variety of systems, in which the computer system takes on the characteristics of human intelligence. The expert systems are designed to act as an expert consultant to a user who is seeking advice about a specific situation.

Tourism and Information and Communication Technologies (ICTs) are two most dynamic motivators of the emerging global economy and the contribution of them to the society is large and diverse. Tourism is an Information intensive industry, which generates a large quantity of information to be processed and communicated (Sheldon, 2003). Poon (1993) argues that 'a whole system of Information Technologies is being rapidly diffused throughout the system. Van hoof et.al (1995) indicate that the most common use of information technology in hotels is concentrated in the front office, reservations, telephone department, and management information systems functions supported by accounting department. Technology can offer significant advantages in operational management such as property management system, tactical management such as financial modeling and yield management and strategic management such as decision support system to hotel organizations (Kim, et.al. 2005). Systems used in hospitality sector include Property management systems, Sales and Marketing System, Back office systems, Revenue management system, Central Reservation system and quality management system. Travel agencies use Global Distribution Systems (GDSs), front office systems, back office systems, agency management systems, supply chain management systems, etc. In addition to those systems used by travel agencies, tour operators use tour planning software specifically. Airlines are pioneers in using information systems since they set the first transaction processing system, called computer reservation systems (CRS). SABRE is the first CRS and later much advancement took place which all helped the CRSs to progress and currently they are transformed into Global Distribution Systems. Baggage and Cargo handling systems, Cargo Movement Systems, Systems used in aircrafts, Safety Systems, Systems for flight scheduling and planning, Crew scheduling and Management, Gate Management and Departure Control System, Automated Ticket Machines (ATMs), Flight Information Display Systems and Immigration Control Systems are some of the major information systems used by airlines and airports together (Dileep, 2011). The ability of destinations to satisfy the information and reservation requirements of buyers efficiently, by providing appropriate and accurate information online, will be critical for their future attractiveness. The term 'Destination Management Systems' come into use over the last decade to describe the Information and Communication Technology infrastructure of a DMO (Buhalis, 2003). Sophisticated destination marketing information systems (Wober, 2003) are there and many destinations have already developed such systems to compete in this modern world.

In Tourism, similar to other sectors, latest developments have been incorporated in the case of Information Systems. Artificial Intelligence (AI) is applied in some of the systems. Expert Systems and Neural Networks are areas where increased System Intelligence is used. Multimedia Information is another emerging area, which Tourism Information Systems accept and use. Applying Semantic Web technologies $\square$ is one of the methods where semantic web technologies are considered as the next generation web, which has the vision of having background knowledge about the meaning of web sources stored in a machine-processable and interpretable way (Wall, 2000). GIS (Geographic Information Systems) based Tourism Information Systems are also available now and such systems are built mainly for giving information to the tourists (Wise, 2002). The major applications of GIS in tourism include Developing tourism resource inventories; Tourism planning while safeguarding the environment; Identifying location suitability under conflicting demands; Monitor and control tourism activities; Tourism marketing; Providing information about tourist destinations over the Internet; Simulate and model spatial outcomes or visual impact analysis; Tourist time-space analysis; Community involvement and participation; and Providing information for decision making for managers as well as consumers (Boyd and Butler, 1996).

\section{METHODOLOGY}

The methodology adopted for this study is given in detail in the following paragraphs.

The study required both primary and secondary data. Especially since the information systems are ever growing and changing field, extensive and up-to-date literature survey was undertaken to find out the current usage of information systems in the international scenario. Secondary data was collected from the various sources including books, journals, published promotional materials and statistics by tourism authorities of Kerala. The study area covers entire Kerala. But the focus of the study is on the areas where tourism activities are being taken place.

Extensive field surveys-sample surveys-were undertaken as part of the study. Primary as well as components of tourism industry such as Hotels, Travel Agencies, and Tour Operating companies along with Governmental agencies like District Tourism Promotion Councils (DTPC) and Department of Tourism, Government of Kerala were surveyed with a structured questionnaire to find out the type of information systems being used as well as to identify the impacts. To have a glance over the efficiency of the available systems, a sample survey was held among the users of the system such as managers/executives of the above organizations and also the tourists who used the services of the organizations mentioned above with a questionnaire. To find out reasons why many establishments are not using Information Systems, a questionnaire-based survey was conducted among those establishments. To discuss about the future, an expert opinion survey was also held afterwards using twenty four statements. The

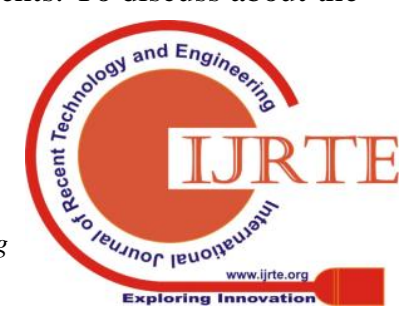


primary data collection held in four phases.

For collecting data from the industry, samples were chosen randomly. Total 132 hotels are there in the category of five star, four star, three star, two star and one star. 4 five star hotels, 6 four star hotels, 16 three star hotels, 11 two star hotels and 5 one star hotels, which constitute $30 \%$ of the total hotels in the above categories, were surveyed. As far as intermediaries are concerned, the main among them, travel agencies and tour operators, were surveyed randomly. According to an approximate estimate based upon the listed IATA approved Travel Agencies and Tour Operating companies in 'Kerala Companion' (published by Department of Tourism, Government of Kerala), there are 200 intermediaries (130 Travel Agencies and 70 Tour Operators) in Kerala. Survey was conducted in 30 Travel Agencies and 22 Tour Operators (42 intermediaries) that constitute $21 \%$ of the total intermediaries. Total 448 tourists (Domestic as well as international) who used the services of the organizations were surveyed. 247 tourists, randomly chosen, stayed at the hotels surveyed were contacted during the survey time in the organizations. 201 tourists visited Kerala either through Travel Agency or through Tour Operators surveyed were also contacted. Interviews were also held with 126 , randomly chosen, top level as well as medium level executives to know about the information availability for them due to the implementation of the various information systems.All DTPCS (14) were contacted through ordinary mail with a structured questionnaire, seven of them responded by sending back the filled in questionnaires. Department of Tourism, Park View office was surveyed by interviewing key personnel over there.

To discuss about the future and to suggest model for further development an expert opinion survey was organized. Twenty four statements were formulated for the survey. Fifty experts were chosen from the field of Information Technology, Management, and Tourism industry. They were asked to respond on five point scale as strongly agree, agree, No opinion, Disagree and Strongly disagree. Two rounds of survey were held as part of this.

The collected data were fed into the computer and analyzed with the help of it keeping in view of the objectives of the study. The data collected were tabulated and percentages, weighted arithmetic mean, standard deviation, chi-square values, Mann-Whitney U Test and Cross tabulation were mainly used for discussion regarding the types of information systems used, impacts of usage of information systems and others. The same tools were used to analyze the data collected to identify the reasons for not using information systems especially small and medium scale establishments. To discuss about the future an expert opinion survey was organized. The statements after getting consensus were considered. The data from collected from the experts in the form of five-point scale was tabulated. Mean value was taken and inter-quartile range was found out, which is considered for consensus. If the value of inter-quartile range is one or less than one, then consensus is considered as arrived.

\section{DISCUSSION AND FINDINGS}

The analysis part includes the findings mainly and the data tables and analysis values are not included due to the space constraints. Tourism in Kerala has been growing during the last twenty years, though some ups and downs were there in some odd years. Number of tourist arrivals in both domestic as well as international categories have increased tremendously. Product range in Kerala has increased in a big way. The activities of Kerala tourism department has been changed from just doing hospitality to the guest to an integrated functioning on development that includes activities on planning, promotion and development. The infrastructure has increased in a tremendous manner and the best example is the accommodation sector. A number of innovative promotional strategies are being taken by the department of tourism, government of Kerala for the promotion of tourism in Kerala. Kerala tourism has been getting national as well as international appreciations for the last several years and they are examples of the performance of Kerala tourism. Altogether Kerala tourism has shown a significant amount of growth during the last twenty years.

\subsection{Type Of Information Systems}

The analysis of the data collected from hotels on the usage of type of information systems in the hotel sector reveals that the surveyed establishments are predominantly using only two systems, accounting information system and credit card readers. None of the systems except computer based information systems, are being used by more than $50 \%$ of the hotels. As a whole from the analysis it can be stated that the usage scenario is not up to the mark. Five star, four star and three star hotels are using information systems considerably. In USA all the top categorized hotels are using all the systems mentioned in the questionnaire. Online bookings are showing dramatic growth. According to Phocuswright.com (www.phocuswright.com), $40 \%$ of the reservations are through Internet based reservation systems and 30\% of the reservations are through on-line travel agencies such as Travelocity and Expedia in large upper class hotels in Europe. More than $95 \%$ of the classified hotels in United States have property management systems . In comparison with international scenarion, the usage of the systems is not up to the mark. Lower categories of hotels are not using the systems considerably. Another study reveals that almost 100 percent of the upmarket hotels in US cities are using all the systems mentioned in the questionnaire. Here also the up market hotels are using a number of systems, but still the usage rate is not as good as that of the developed countries. But overall usage scenario is not comparable.

The study reveals that the presence of computer reservation systems/global distribution systems and accounting information systems in travel agencies is considerably high. $80 \%$ of the surveyed organizations have accounting information systems. More than $90 \%$ of the centers have computer reservation system/global distribution systems terminals. The presence of other internationally used systems is only limited to a few travel agencies and supply chain management systems are not being used by any of the surveyed centers. By 1995, 100\% of the travel agencies in USA started to have terminals of major GDSs. As per this study, more than $90 \%$ of the respondents are using CRS/GDS. Also almost $100 \%$ of the large travel agencies use all the information systems mentioned in the questionnaire. An examination of the respondents of the sample reveal that majority of the Travel Agents are either small scale or medium scale organization, 
especially small and tiny organizations in terms of size and volume of transactions. $30 \%$ of the reservations are through on-line travel agencies such as Travelocity and Expedia in large upper class hotels in Europe. The situation in Kerala is not up to the mark in comparison with that. As per the survey, GALILEO is the most used Computer Reservation System among the surveyed travel agencies where as AMADEUS comes next.

The sample based study reveals that the presence of information systems in tour operating companies is not very significant. $82 \%$ of the surveyed organizations have accounting information systems. $50 \%$ of the centers have computer reservation system terminals. Only these two systems are considerably used by the surveyed tour operating companies in Kerala. The majority of the surveyed centers do not have other internationally categorized information systems. In Europe and American countries all the major systems are used, and also some other specialised systems like recommender systems are also used by the large tour operators. A close examination of the sample reveals that a vast majority of the agencies surveyed are either very small, small or medium level organizations. The usage scenario is not in a position to match with international level. As per the survey, $50 \%$ of the total surveyed centres have CRS/GDS terminal. Here also, as in the case of travel agencies, GALILEO is the most used Computer reservation System among the surveyed tour operators in Kerala.

Kerala as a tourist destination does not have an integrated information system as is available in the case of destinations in Europe and America. A few systems were set up, as per the authorities, but it was found that such systems were not all inclusive and found that majority of them are either not in use or not being implemented due to technical reasons. The survey held with the authorities reveal the destination Kerala have not yet implemented the concept of Destination Management Organization/Company and hence the scope of a destination management/marketing information systems is not there.

Government agencies, due to many reasons, are not yet tried to establish the concept of computer based information systems. Even networking of the agencies is not being done. DTPCs, the developmental agencies at the district level are also not using information systems in the proper sense.

\subsection{Performance of the information systems}

The usage of information systems by the sample of tourism industry which includes hotels and intermediaries resulted in the benefits such as workload of the employees have reduced, information access became easier, redundancy of usage of information minimized and overall efficiency of operations considerably increased. Also a simple majority has agreed that implementation of information systems benefited in reducing the number of employees and in making the day-to-day operations easier. The most important factor to be considered that the study could not find from the sample the most important function as well as benefit of usage of information system-managers decision making became easier-as a result of usage of information systems in theirs working environment which denotes that majority of the systems used in the organizations may be used at the operational level. The survey reveals that among the responded agencies, employee number reduction is predominantly experienced up to $5 \%$. Lions share of the sample (more than $80 \%$ ) experience that quantity of employee reduction is up to $5 \%$ of the total number of employees worked with the establishment before the implementation of information systems in their working environment.

The usage of information systems by the sample of hotels resulted in the benefits such as workload of the employees have reduced, day to day operations became easier, information access became easier, redundancy of usage of information minimized and overall efficiency of operations considerably increased. Also a simple majority has agreed that implementation of information systems benefited in reducing the number of employees. The most important factor to be considered that the study could not find from the sample the most important function as well as benefit of usage of information system-managers decision making became easier-as a result of usage of information systems in theirs working environment which denotes that majority of the systems used in the organizations may be used at the operational level.

The survey reveals that among the responded agencies, employee number reduction is predominantly experienced up to 5\%. Lion's share of the sample (more than $80 \%$ ) experience that quantity of employee reduction is up to $5 \%$ of the total number of employees worked with the establishment before the implementation of information systems in their working environment.

The survey also reveals, that out of the surveyed five star and five star deluxe hotels in Kerala, the presence/utility of computer based reservation systems is very high. Seventy five percent of the hotels get reservations/sales above $50 \%$ through computer based reservation systems in comparison with other methods used for the study. In four star hotels in Kerala, traditional methods are still the major tool for reservation/bookings for hotel rooms. The next major method for reservation/booking is Email. Computer based reservations are there in more than $80 \%$ of hotels surveyed, but in comparison with the five star hotels, the share in this category is less. Among the surveyed three star hotels in Kerala, traditional methods are the major tool for reservation/bookings for hotel rooms. The next major method for reservation/booking is E-mail. All the three star hotels surveyed are getting reservation through computer based reservation systems. The share of reservation/sales among the surveyed three star hotels as far as computer-based reservation systems are concerned is very less as compared to five star as well as four star hotels. Lower category has limited use of ICT in this area.

The usage of information systems by the sample of intermediaries resulted in the benefits such as number of employees reduced, workload of the employees was reduced, information access became easier, redundancy of usage of information minimized and overall efficiency of operations considerably increased. The most important factor to be considered that the study could not find from the sample the most important function as well as benefit of usage of information system-managers decision making became easier-as a result of usage of information

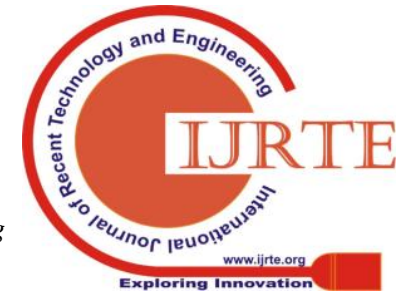


systems in theirs working environment which denotes that majority of the systems used in the organizations may be used at the operational level. Also the opinion that day-to-day operations became easier was not supported by vast majority.Lions share of the surveyed intermediaries (more than $80 \%$ ) experience that quantity of employee reduction up to $5 \%$ of the total number of employees worked with the establishment before the implementation of information systems in their working environment.

The survey done in tour operating companies to find out the benefits of information systems reveals the following. Majority of the respondents are of the opinion that the usage of information systems in tour operation generates the benefits such as workload of employees reduced; day-to-day operations became easy; information access became easier; redundancy of information could be minimized; and the efficiency improved. But in the survey, majority did not agree to the view that usage of information systems resulted in employee number reduction and making managers' decision more easily. Minority of them experience employee number reduction up to $5 \%$. The surveyed travel agencies are of the opinion that the usage of the advanced information systems resulted in employee reduction; reduced work load for employees; day to day operations became easier; managers could take decisions more easily; information could be accessed more easily; redundancy of information and data could be minimized; and efficiency level improved. Majority of the travel agencies are of the opinion that they experience employee number reduction up to $5 \%$.

No major information systems are being used at the destination level like tourism destination management/marketing information system. Hence the question of benefits does not arise.Also the governmental agencies are yet to be tapped the potential of information systems and hence the benefits of information systems do not arise.

\subsection{Performance of information systems: evaluation by users}

The analysis of the data received from the tourists stayed at the surveyed hotels reveals that good majority of them are of the view that the information received from the organizations are of quality. But yet, the majority responded that the accuracy/preciseness and time in getting the information provided have to be improved for better quality. Performance evaluation of information systems by tourists used the services of tour operators/travel agencies: As per the analysis, majority of the tourists are of the opinion that information they receive is of good quality. Only a minority has the opinion that the quality of information they get is poor. Less than half percent of the respondents viewed that the characteristics of quality information such as preciseness, accessibility and time are to be improved.Good majority of the respondents are of the view that the quality of the information they receive from the organization is good. But a simple majority has suggested that for the better performance, preciseness and accessibility have to be improvised.As discussed earlier, government agencies do not have any formal computer based information systems and the performance evaluation from the opinion of the users of the systems do not arise.A big majority of the respondents view that the quality of information available on Keralatourism is not up to the mark. They have suggested that for the better performance, preciseness, time in getting information and accessibility have to be improvised. The executives working in the surveyed hotels are also not having a different opinion.As far as performance of the information systems present in the tourism industrial components such as hotels, travel agencies, and tour operators are concerned, the quality of information being provided to the users are good according the majority of the surveyed participants. But yet, they are also of the opinion that it would be better if the exactness and accessibility is improved. But the users of the information at the destination as well as government level, the availability of quality information is poor and preciseness, accessibility and time in retrieving information have to be improved considerably.

\subsection{SMEs in tourism and use of ICT}

An investigation was done to find out the causes why mainly small as well as medium establishments are not using information systems considerably. The study reveals that majority of the surveyed hotels (3,2 and 1 star) and intermediary organizations have not implemented the modem information systems considerably and an attempt is made to identify the reasons. The main reasons were categorized into four areas. They are financial, lack of awareness, mindset related and technology related reasons. The first aspect was accepted by the respondents - the majority of the respondents are of the view that implementation of such information systems require lot of human resource for purchasing and introducing the systems as well as for enabling employees to operate the systems-by giving training and others. The analysis on the second area could not prove the lack of awareness. The next three variables focused on the mindset of the authorities. Majority of the respondents are of the opinion that only large organizations require modern information systems and implementation of them will alter the existing pattern of work. A simple majority is also of the opinion that too many information systems may generate confusion among employees. The last two variables were on technology and the associated issues. The majority is of the opinion that the Information technology related concepts and devices/systems are frequently changing which is one issue before going for implementing information systems. The last issue was on Implementation of information systems require lot of technology infrastructure along with skilled human resource which will be difficult to manage and a simple majority agreed, but not convincingly.

The net result is that mainly due to three major reasons the respondents are not using the modern information systems such as financial reasons, mindset related reasons and technology related reasons. As per the opinion of the sample, while discussing in detail, huge financial resources are required for implementing such systems and also to give training correspondingly. Many systems are not being used since they are of not much use as per their knowledge and also not interested to alter the existing pattern of work by implementing the systems. Frequent developments occur in Information Technology that is a difficulty to cope with since many of the softwares/devises have to be changed accordingly. In addition to the 
above reasons, public sector agencies are facing few other hindrances like conceptual difficulty that hints that only paper-based matters are considered as documents. Information systems basically intended in doing transactions/dealings maximum over networks. Lack of awareness about the benefits and trends on information systems along with procedural issues are also major problems faced by public sector agencies to go for information systems in their working environment.

\section{VI.THE FUTURE}

Since it was found from the study that especially small as well as medium establishments are not using the information systems considerably and the presence of information systems in the destination level is very less, to discuss about the future, an expert opinion survey was conducted and the survey reveals the following. An expert group of information technology, tourism and management professionals has to be formed to eliminate the gap between technology evolution and market needs in the destination as well as the government level in relation to tourism. Conducting primary data collection and doing studies is an inevitable one for any business sector to remain competitive. In the case of Information technology and related aspects it is very essential especially since the field faces frequent changes and developments. Authorities have to organize many activities for disseminating information on different aspects of tourism in the world, changes happening, technology changes, etc. to the industry in its jurisdiction. This is very important especially in the case of small and medium enterprises for which the international exposure will be limited. In the case of information systems also, either the NTO or the concerned agencies/authorities can take up the responsibility for organizing various programmes aimed at disseminating the relevant information. The same can be organized for different categories of stakeholders in the tourism sector like higher-level managers of organizations in the tourism sector, executives, owners/proprietors of businesses related to tourism, etc.

Some groups can be formed under cooperative basis, which will be useful for the industry since majority of the establishments are either small or medium scale organizations who will be facing problems for implementing and managing information systems in their establishments. The members of the associations can be initiated to think of implementing information systems and also to share the systems with other members in a possible manner. Seminars, Orientation programmes, workshops, evolving consortiums, etc. will help to disseminate ideas as well as to inspire them to go ahead with the use of information systems. Forming quality circles as well as consortiums of different firms from the tourism industry in Kerala along with multinational firms with Information technology exposure will surely benefit in information sharing and understanding what is happening in relation to this outside the destination. In many situations offer of financial assistance will energize the entrepreneur to think positively.

As we discussed earlier associations and cooperative agencies which are formed/ going to be formed with the aim to share the benefit of information systems may be given some offers in financial terms like loans to bear the capital expenses, subsidies for certain items, etc. and this may encourage them either to form groups or to implement high end systems for the maximum utility of information systems. Training for the users is an inevitable part whenever any new kind of technology related aspects are being adopted/implemented in an organizational set.

The availability of quality information required by the tourists and the stakeholders of tourism in Kerala is limited. Industry stakeholders such as hotels, travel agencies, tour operators and others require proper, accurate and timely information about tourism market, demand and others for the better performance. Apart from the industrial stakeholders, other groups like Policy makers; planners and professionals working with governmental agencies also require such information. Students, Teachers of tourism, Researchers, journalists, etc. are some other categories of users of information on tourism. Tourists are another category, which require extensive information about the destination. Tourists require data and information about the destination for making a decision.

Information systems are the systems that collect, process and provide relevant, accurate and needed information to the users. It has to be accepted that information systems are the best solutions for handling the large volume of data. As discussed, a general information system is required for the entire tourism stakeholders in tourism. Setting up of a Destination management/marketing information system-one of the best systems used internationally-will beuseful for the tourism industry stakeholders in Kerala. Destination management systems are being introduced by many international tourism destinations. The applicability of such systemsare many and mainly they collect data about tourism in the destination and process them to give proper information to the users as per their requirements. Collection, selection and processing of data and information, providing the information required by the users, act as an information center for various training and educational and other agencies, act as a consultancy agency for the information required groups, promotion and exchange of information with other similar documentation centers in different parts of the world, etc. could be the major functions of the system.

The system can have two categories of users such as internal-users from the developing agency and external-industrial and other users. Secondary data sources for the system can be many like tourist surveys, publications, annual reports, survey of private agencies, etc. Data from local and regional tourism bodies, trade associations, international tour operators, academic studies, newspapers, national/ regional travel surveys, tourism related publications, international agencies like WTO, WTTC, etc. Apart from that secondary data can be updated from the industry stakeholders such as hotels and others. Data can be collected exclusively from the destination as well as from the markets possible for finding out trends and others. The data sources for the primary research can be market researches, surveys by the agency, which is managing this systems, etc..

Dissemination of the information produced by the system is another crucial are in the establishment of destination information systems. All the 
information cannot be given to all the users. Restrictions have to be set up and security of the information being processed has to be ensured. Information can be disseminated in different formats like summary reports, annual reports, specific reports, search results using key words, electronic products, electronic news letter, etc. Internet is one of the best channels for the distribution of information worldwide. The external users can be charged nominal fee for availing data and information. Setting up of the system as well as maintenance of it will require large amount of financial resources. If the users are charged a nominal fee, the maintenance of the systems can be done by it.

Along with this system, developing a GIS would be more beneficial for the tourism in Kerala. GIS is one of the best systems for analyzing large databases and to look for trends and patterns that are not apparently visible from charts and tables from other statistical techniques as they do not consider the space dimension of a particular record. This GIS have to be developed exclusively for the tourism in Kerala with information on attractions, facilities, geographical features, fairs and festivals, destinations, training institutes in tourism, distances among places, routes to destinations, etc. The major beneficiaries of the system will be tourists, tour operators, travel agents, NGOs, Policy makers, Planners, etc.

Since we have already discussed about the MIS for the destination, it would be better if interface were developed between MIS and GIS. The advantage is that the users can access data from both without altering the database of each other. For making the information in the global level a good portal has to be set up. It will be better that the Department of Tourism, Government of Kerala can to take up initiative to set up both the systems. This can be entrusted with a specialized agency including experts in the field of information systems under the department. Outsourcing is the common practice in these cases. Discussion suggests to set a Marketing Information Systems at the Destination level and also to develop a Geographical information system for the Kerala tourism with all the required data and information on tourism and related fields. Both the systems can have interface and the governmental agency can take lead role in establishing it as an autonomous agency with giving due role to the private agencies. Outsourcing can be done in the beginning.

\section{SUGGESTIONS AND SCOPE FOR FURTHER STUDY}

The most important suggestion is that an expert group of information technology, tourism and management professionals has to be formed to eliminate the gap between technology evolution and market needs in the destination as well as the government level in relation to tourism. Government has to initiate certain programmes and events to motivate the small as well as medium agencies in tourism to come up and to adapt to the latest changes in the field of information technology and also the information systems. E-governance has to be initiated in the governmental agencies in relation to tourism. Though, some news is there in relation to this, but the proper utility has generated yet.

Department of tourism and its agencies like KTDC, KITTS, BRDC, Ecotourism Directorate, DTPCs, have to link technologically together using latest Information Technology to exchange information among one another with the help of Internet and intranets. Information systems have to be developed, keeping in mind the limitations may arise due to the governmental rules and regulations, inside the department of tourism to make the information retrieval faster and also in transacting and exchanging information in a speedier way. A database can be set up exclusively for the governmental use.Small and medium agencies have to come up with more information systems as per the requirements of the users. The officers in the government agencies have to be given proper training to develop skills to utilize Information technology maximum and also to change the mindset to be adapted to the technology filled modern working environment.

The study opens up many areas for further studies. Major of them includes: Strategic use of information technology in public agencies; application of Information Technology as a strategic tool for the promotion; Geographic Information Systems for tourism, developing a technology architecture for Kerala; Kerala Tourism-Destination Management information System; developing a technology architecture Kerala; usage of Information systems: a comparative study of large establishments with small establishments in tourism in Kerala; ND application of GIS in Tourism: an analytical study for the wildlife tourism in Kerala.

\section{REFERENCES}

[1] Bardi A James, 2003, Hotel Front Office Management, IIIrd Edition, John Wiley, New Jersey, 421.

[2] Boyd and Butler, (1996), Seeing the forests through the trees; using GIS to identify potential ecotourim sites in Northern Ontarion, In L.C.Harrison and W Husband (eds), practicing responsible tourism:International case Studies in Tourism planning, Policy and Development.

[3] J.Wiley and Sons, New York, Pp 404-421.

[4] BuhalisDimitrios, (1996), I T as strategic tool for tourism and hospitality management in the new millennium, Tourism Review,2,Pp 34-36.

[5] Christo doulakis, et.al, (2004), Minotaurus; Distributed Multimedia Tourism Infromation Systems (PDF version in Internet), Multimedia Systems Institute of Crete (MUSIC), Technical University of Crete, Greece.

[6]Cooper Chris, Fletcher John, Gilbert David and Swanhill Stephen, (1993), Tourism-principles and Practices, Pitman with EL/BS, London.

[7] Dileep M R., 2018. Tourism: Concept, Theory and Practise, IK International, New Delhi

[8] Dileep, M.R., 2011, Information Systems in Tourism, Excel Books, New Delhi

[9]FarsariYianna, farsari@iacm.forth.gr, Research scholar, University of Surrey, UK in collaboration with FORTH,Greece, Published in Internet, accessed on 23/08/04.

[10] Inkpen Gary, 1998, Information Technology for travel and Tourism, Addion Wesley Longman Limited, Esex, England.

[11] Jaiswal M and Mital M (2004), management Information System, Oxford University Press, new Delhi.

[12] Kim BH, Singh AJ, and Huh C, 2005, Information technology Practices and performance Impacts-A Case of Korean Hotel Industry, Journal of Hospitality and Tourism, 3, 1-20.

[13] Koontz Harold and Weirich Heinz, 1990, Essentials of Management, $5^{\text {th }}$ edition, Tata McGrawHill, New Delhi.

[14] Laudon K and Laudon J, (2004), Management Information System-Managing the digital Firm, $8^{\text {th }}$ edition,Prentice Hall, India:08.

[15] Maedchea Alexander, Staab Stephen, (2004), Applying Semantic Web Technologies for Tourism Infromation Systems, (PDF,Internet), Research Center for Information technology, University of Karlsruhe, WIM, Germany 
[16] McAdam,D.(1999), The value and cope of GIS in Tourism management, Journal of Sustainable Tourism, 7(1), 77-98.

[17] O'Brien, (1998), Management Information Systems-A managerial perspective, Galgotia, New Delhi:06.

[18] Poon A, 1993, tourism, technology and competitive strategies, CABI, Oxford.

[19] Ran Dejan, DjordeviSlobodanka, Kajan, Stoimenovleonid, To VCladimir, (2004), Some applications of the Multimedia GIS in Tourism, (PDF,Internet), Faculty of Engineering, University of Ni, Yugoslavia.

[20] Ritchie JBR, Ritchie JR, (2002), Framework for an industry-supported destination marketing information system, Tourism management, 23, Pp439-454.

[21] Schafer,J.B, Konstan J, Riedl.J, (2001), E-Commerce ,Recommender Applications, Journal of data mining and knowledge discovery, 5, 115-53.

[22] Scheldon P, Wober K and Fesenmalec D (Eds), (2001), Information and Communication technologies in tourism, Springer Verlag, Vienna.

[23] Senn A James, 1989, Analysis and Design of Information Systems, McGraw Hill international Edition, Singapore.

[24] Sheldon J Pauline, 2003, Tourism Information Technology, CABI publishing, Oxon, UK.

Stair Ralph and Reynolds George, 2001, Principles of Information System Thomson Learning, Singapore

[25] Stair Ralph and Reynolds George, 2001, Principles of Information System, Thomson Learning, Singapore:04.

[26] Turban, Rainer and Potter,2002, Introduction to Information Technology, John Wiley and Sons, Singapore.

[27]Van Hoof, HB, Collins GR, Combrink TE and Verbeteen MJ, 1995 , Technology needs and perceptions: Assessment of the US lodging industry, Cornell Hotel and Administration, 36 (5), 64-69.

[28] Wall Geoffrey, (2000), Geographic Information System, In JafarJafari (Chief Editor),Encyclopedia of Tourism, Routledge, London.

[29] WerthnerHannes, Klein Stefan, 1999, Information Technology and Tourism-a challenging relationship, Springer Wien, New York.

[30] Whitten, Bentley and Dittman, 2002, Systems Analysis and Design, Galgotia, New Delhi.

[31] Williams P W, Paul J and Hainsworth, (1996), Keeping track of what really counts: Tourism resource inventory system in British Columbia, Canada, In L.C.Harrison and W Husband (eds), practicing responsible tourism:International case Studies in Tourism planning, Policy and Development, J.Wiley and Sons, New York, Pp 404-421.

[32] Wise Stephen, (2002), GIS basics, Taylor \& Francis, London.

[33] Wober W Karl,(2003), Information supply in tourism management by marketing decision support systems, Tourism management, $24, \mathrm{Pp}$ 241-255.

[34] WTOBC, (2001), eBusiness for Tourism: Practical guidelines for destinations and businesses, World Tourism Organisation, Madrid.

[35] www.tourmis.com, the official website of Tour MIS, Austria, data accessed on $16 / 6 / 04$

[36] Yianna Farsari, (2004), GIS Based support for sustainable tourism planning and policy making (Internet, PDF), University of Surrey and FORTH, Greece 